\title{
Maternal Hb during pregnancy and offspring's educational achievement: a prospective cohort study over 30 years
}

\author{
Mohammad Fararouei ${ }^{1}$, Claire Robertson ${ }^{2}$, John Whittaker $^{3}$, Ulla Sovio ${ }^{4}$, Aimo Ruokonen ${ }^{5}$, Anneli Pouta ${ }^{6}$, \\ Anna-Liisa Hartikainen ${ }^{7}$, Marjo-Riitta Jarvelin ${ }^{4,6,8} \dagger^{*}$ and Elina Hyppönen ${ }^{9} \dagger^{*}$ \\ ${ }^{1}$ Faculty of Health, Yasuj University of Medical Sciences, Yasuj, Iran \\ ${ }^{2}$ School of Life Sciences, University of Westminster, London, UK \\ ${ }^{3}$ London School of Hygiene and Tropical Medicine, London, UK \\ ${ }^{4}$ Department of Epidemiology and Public Health, Imperial College London, Norfolk Place, St Mary's Campus, \\ London W2 IPG, UK \\ ${ }^{5}$ Institute of Diagnostics, University of Oulu, Oulu, Finland \\ ${ }^{6}$ National Institute of Health and Welfare, Oulu, Finland \\ ${ }^{7}$ Department of Clinical Medicine/Obstetrics and Gynaecology, University of Oulu, Oulu, Finland \\ ${ }^{8}$ Institute of Health Sciences, University of Oulu, Biocenter Oulu, PO Box 5000, Fin-90014 Oulu, Finland \\ ${ }^{9}$ MRC Centre of Epidemiology for Child Health, Centre for Paediatric Epidemiology and Biostatistics, UCL Institute of Child \\ Health, 30 Guilford Street, London WCIN IEH, UK
}

(Received 7 October 2009 - Revised 27 April 2010 - Accepted 28 April 2010 - First published online 4 June 2010)

\begin{abstract}
The aim of the present study was to examine the association between maternal Hb levels during pregnancy and educational achievement of the offspring in later life. We analysed data obtained from the Northern Finnish Birth Cohort Study conducted in 1966, in which, data on mothers and offspring from pregnancy through to the age of 31 years were collected. The cohort comprised 11656 individuals born from singleton births (51\% males and $49 \%$ females). Maternal Hb levels were available from the third, seventh and ninth gestational months. Educational achievement was measured as school scores (range 4-10) taken at the ages of 14 (self-reported questionnaires) and 16 (school reports) years as well as the highest level of education at the age of 31 years. The present results showed a direct positive association between $\mathrm{Hb}$ levels and educational achievement in later life. After adjustment for sex, birth weight, birth month and a wide range of maternal factors (parity, smoking, mental status, whether pregnancy was wanted or not, education, social class and marital status), only maternal Hb levels that were measured at the ninth month were significantly associated with the offspring's school performance. If the levels were $\geq 110 \mathrm{~g} / \mathrm{l}$ at all the three measurement points, offspring not only had better school scores at the ages of 14 and 16 years $(\beta=0 \cdot 048, P=0 \cdot 04$ and $\beta=0.68, P=0.007$, respectively), but also had an increased odds of having a higher level of education at the age of 31 years $(\mathrm{OR}=1 \cdot 14$, $P=0.04)$. The present study suggests that low maternal $\mathrm{Hb}$ levels at the final stages of pregnancy are linked to the poorer educational achievement of the offspring. If our observation is confirmed, it would suggest that Fe prophylaxis even at fairly late stages of pregnancy may be beneficial for the subsequent health of the offspring. However, more studies are needed to fully establish the potential pathways and the clinical importance of the present findings.
\end{abstract}

School achievement: Higher education: Maternal Hb: Cohort study

$\mathrm{Hb}$ is an Fe-containing metal protein found in the erythrocytes, and is responsible for $\mathrm{O}_{2}$ transportation in vertebrates. In addition to being bound to $\mathrm{Hb}, \mathrm{Fe}$ is found in cells throughout the human body, and is crucial for multiple metabolic processes, which range from DNA synthesis to electron transportation $^{(1,2)}$. As defined by the WHO, Fe deficiency is the most common nutritional disorder and the leading cause of anaemia in the world. A quarter of the world's population, i.e. 1.6 billion people, are estimated to be anaemic, with pregnant women and children being the most vulnerable to this deficiency ${ }^{(3)}$. Anaemia is commonly defined as $\mathrm{Hb}$ levels below $138 \mathrm{~g} / 1$ in men, $121 \mathrm{~g} / \mathrm{l}$ in women, and $110 \mathrm{~g} / \mathrm{l}$ in pregnant women and in children.

Through its complex role in oxidative metabolism and in the synthesis of neurotransmitters and myelin, the importance of $\mathrm{Fe}$ in normal neurological functions is increasingly being recognised $^{(4)}$. However, with $41.5 \%$ of the global population of pregnant women (European $18.7 \%$ and African $55.8 \%$ )

Abbreviation: NFBC, Northern Finnish Birth Cohort.

* Corresponding authors: M.-R. Jarvelin and E. Hyppönen, email m.jarvelin@imperial.ac.uk; e.hypponen@ich.ucl.ac.uk

$\dagger$ Both authors M.-R. J. and E. H. contributed equally to the work. 
being anaemic ${ }^{(5)}$, there is still a shortage of studies examining the association between $\mathrm{Fe}$ deficiency and early brain development.

Studies in rodents have shown that pregnant rats fed on an Fe-deficient diet during both early gestation and lactation give birth to offspring with lower Fe concentrations in the brain ${ }^{(6,7)}$. Fe supplementation in mid-gestation or immediately following delivery did not raise the brain Fe concentration as expected, with dams and pups exhibiting significantly poorer cognitive performance. Human studies also suggest an association of Fe deficiency and supplementation, particularly in early life, with long-term cognitive development ${ }^{(8-10)}$. However, there are no studies examining the relationship of maternal $\mathrm{Fe}$ status (as a marker for pre-natal exposure) with offspring's long-term cognitive development. Using data obtained from the 1966 Northern Finnish Birth Cohort (NFBC 1966) study, we examined the association between maternal $\mathrm{Hb}$ levels during pregnancy and later educational achievement to obtain further insights into the possible long-term influences of Fe status in utero.

\section{Methods \\ Population}

The NFBC 1966 dataset comprises data pertaining to the births in the two northernmost provinces of Finland (i.e. Oulu and Lapland) during 1966 (live births $n$ 12 058, coverage $96 \%)^{(11)}$. Data on mothers were collected through questionnaires/interviews and records at communal maternal welfare centres during routine antenatal visits; mothers were recruited for the study between the twenty-fourth and the twenty-eighth gestational weeks. Of these, $9.7 \%$ of the data were completed in later pregnancy or after birth. Children were followed into adulthood, and data were collected at birth and at 14 and 31 years of age using hospital records/official national registers and self-administered questionnaires/interviews. In the present study, we analysed data on individuals with written informed consent and born from singleton pregnancies. Data pertaining to socio-demographic status, behaviour, whether pregnancy was wanted or not, mother's educational status, mother's emotional status and smoking were extracted from this dataset for analysis ${ }^{(12,13)}$.

\section{Measures}

Maternal $\mathrm{Hb}$ levels were measured at the third, seventh and ninth gestational months during antenatal visits at health centres or hospitals. Seven different methods available at that time were used, i.e. Tallqvists table, Ljungberg, Sicca, Sahli, Vatatron-Fotom, Erka and Linson Junior. In order to make the results comparable, they were standardised and scaled to grams per litre by clinical and laboratory experts and by the research team. Information on maternal Fe supplementation was not available.

Data on school performance were acquired at 14 and 16 years of age through scores given by teachers. Scores ranged from 4 to 10 on theory subjects such as physics, mathematics, chemistry, the first and second national languages, foreign languages, biology, religion/ethics, social studies, history, geography and natural sciences (given as separate scores/subject and as an overall performance score), and overall score of all subjects, which was calculated as the average of scores given on theory subjects and practical subjects (i.e. music, visual art, health education, crafts, physical education and household economics, available at both 14 and 16 years of age). Information on school performance at the age of 14 years was obtained through self-administered questionnaires sent to the adolescents or to the parents, if the adolescents did not respond (total response $n$ 9983, 86\% of the study sample). Information on school achievement at the age of 16 years was extracted directly from school reports ( $n$ 10474, $90 \%$ of the study sample). School scores at the ages of 14 (self-reported) and 16 (reported by the school) years were highly correlated (intraclass correlation coefficient $=0 \cdot 9$ ), suggesting a good reliability for the selfreported scores. Information on higher educational status, with details of university degree if present, was acquired through a postal questionnaire at the age of 31 years ( $n$ 8427, $72 \%$ of the study sample). The present study was conducted in agreement with the Declaration of Helsinki, and all procedures involving human subjects were approved by the University of Oulu ethics committee. Written informed consent was obtained from all the subjects.

\section{Statistical analysis}

The ANOVA or Student's $t$ test was used to run the statistical analysis to examine the association between background variables and maternal $\mathrm{Hb}$ levels during pregnancy and school scores of the offspring (Table 1). The $\chi^{2}$ test was used to analyse the association between background covariates and the level of education at the age of 31 years. The association of persistent anaemia $(\mathrm{Hb}<110 \mathrm{~g} / \mathrm{l}$ measured at all points, $n$ 39) and intermittent anaemia ( $n$ 1440, $\mathrm{Hb}<110 \mathrm{~g} / \mathrm{l}$ in either the third ( $n$ 823), seventh $(n$ 869) or ninth $(n$ 376) month of gestation) with educational achievements was also examined by fitting separate models. Multiple linear regressions were run for continuous outcomes (school scores) by assuming a linear relationship between the variable and its predictors. Residual plots were checked for the model assumptions. Logistic and polytomous regressions were run for binomial and categorical variables. Analyses were first performed using linear or logistic regression to examine the sexadjusted association between the predictors and the outcomes. Among the available information (i.e. sex, gestational age, birth weight and length, child's calendar month of birth, mother's educational status, whether pregnancy was wanted or not, social class, parity, mother's marital status at pregnancy, mother's smoking status during pregnancy, mother's mental status, father's social status, mother's weight, mother's height and child's Fe supplementation during infancy), factors were selected as covariates in the final model if a significant improvement in the goodness of fit of the model was achieved. The proportion of participants with missing data varied by covariate, ranging from $0 \%$ for sex to $27.7 \%$ for information on higher education at the age of 31 years. We imputed (five times) the data to replace the missing values using the multivariate imputation by chained equations package ${ }^{(14)}$. Statistical analysis was run by $\mathrm{R}$ (2.3.0) package ${ }^{(15)}$. 
Table 1. Maternal $\mathrm{Hb}$ at the ninth month of pregnancy, offspring school score at the age of 16 years and proportion with higher education at the age of 31 years by background variables in the 1966 Northern Finnish Birth Cohort study

(Mean values, standard deviations, $n$ and percentages)

\begin{tabular}{|c|c|c|c|c|c|c|c|c|}
\hline & \multicolumn{3}{|c|}{$\begin{array}{l}\text { Maternal } \mathrm{Hb} \text { at the ninth month } \\
\text { of pregnancy }\end{array}$} & \multicolumn{3}{|c|}{$\begin{array}{l}\text { Offspring school score at the } \\
\text { age of } 16 \text { years }\end{array}$} & \multicolumn{2}{|c|}{$\begin{array}{l}\text { Offspring with } \\
\text { higher education }\end{array}$} \\
\hline & Mean & SD & $n$ & Mean & SD & $n$ & $n$ & $\%$ \\
\hline \multicolumn{9}{|l|}{ Sex } \\
\hline Female & $124 \cdot 29$ & $10 \cdot 61$ & 5433 & $7 \cdot 83$ & 0.89 & 5150 & 2286 & $52 \cdot 00$ \\
\hline Male & $124 \cdot 64$ & $10 \cdot 82$ & 5659 & $7 \cdot 21$ & 0.91 & 5324 & 1229 & 30.49 \\
\hline $\begin{array}{l}\text { Unknown } \\
P\end{array}$ & $\begin{array}{l}\text { NA } \\
0.086\end{array}$ & NA & 0 & $\begin{array}{c}N A \\
<0.001\end{array}$ & NA & 0 & $\begin{array}{l}\text { NA } \\
<0.001\end{array}$ & NA \\
\hline \multicolumn{9}{|l|}{ Birth weight (kg) } \\
\hline$>2.5$ & $125 \cdot 33$ & $12 \cdot 88$ & 256 & $7 \cdot 37$ & 0.92 & 273 & 77 & 35.48 \\
\hline$\leq 2.5$ & 124.45 & $10 \cdot 67$ & 10835 & 7.52 & 0.95 & 10200 & 3438 & 41.88 \\
\hline Unknown & $136 \cdot 00$ & NA & 1 & 8.3 & NA & 1 & NA & NA \\
\hline$P$ & 0.28 & & & 0.01 & & & 0.07 & \\
\hline \multicolumn{9}{|l|}{ Child's order* } \\
\hline First & $124 \cdot 79$ & $10 \cdot 47$ & 546 & $7 \cdot 67$ & 0.93 & 531 & 229 & $54 \cdot 14$ \\
\hline Second & $125 \cdot 36$ & $10 \cdot 31$ & 2801 & $7 \cdot 68$ & 0.94 & 2717 & 1151 & $52 \cdot 77$ \\
\hline Higher & $124 \cdot 25$ & $10 \cdot 86$ & 7190 & 7.47 & 0.95 & 6957 & 2090 & 37.08 \\
\hline Unknown & $122 \cdot 41$ & $10 \cdot 75$ & 555 & $6 \cdot 86$ & 0.92 & 269 & 45 & 24.06 \\
\hline$P$ & $<0.001$ & & & $<0.001$ & & & $<0.001$ & \\
\hline \multicolumn{9}{|c|}{ Mother's age (years) } \\
\hline$>20$ & $124 \cdot 14$ & $10 \cdot 35$ & 831 & $7 \cdot 35$ & 0.90 & 704 & 201 & 35.45 \\
\hline $20-35$ & $124 \cdot 61$ & $10 \cdot 65$ & 8551 & 7.54 & 0.96 & 8114 & 2812 & $43 \cdot 16$ \\
\hline$<35$ & 123.91 & $11 \cdot 22$ & 1664 & 7.49 & 0.94 & 1609 & 490 & 37.61 \\
\hline Unknown & 124.54 & 11.72 & 46 & $7 \cdot 19$ & 0.95 & 47 & 12 & 28.57 \\
\hline$P$ & 0.034 & & & $<0.001$ & & & $<0.001$ & \\
\hline \multicolumn{9}{|c|}{ Mother's civil status* } \\
\hline Married & 124.55 & $10 \cdot 72$ & 10670 & 7.53 & 0.95 & 10077 & 3419 & $42 \cdot 17$ \\
\hline Single & $122 \cdot 13$ & $10 \cdot 59$ & 406 & $7 \cdot 25$ & 0.92 & 382 & 90 & 29.51 \\
\hline Unknown & $126 \cdot 00$ & 8.45 & 16 & 7.55 & 1.23 & 15 & 6 & $42 \cdot 86$ \\
\hline$P$ & 0.001 & & & $<0.001$ & & & 0.001 & \\
\hline \multicolumn{9}{|c|}{ Mother's educational status* } \\
\hline None & 124.01 & $10 \cdot 77$ & 139 & $7 \cdot 13$ & 0.90 & 132 & 20 & $19 \cdot 61$ \\
\hline Basic & $124 \cdot 22$ & $10 \cdot 86$ & 7105 & $7 \cdot 36$ & 0.92 & 6609 & 1778 & $33 \cdot 31$ \\
\hline Higher & $125 \cdot 07$ & $10 \cdot 39$ & 3682 & $7 \cdot 84$ & 0.94 & 3560 & 1672 & 58.54 \\
\hline Unknown & 121.97 & 11.48 & 166 & 7.35 & 0.94 & 173 & 45 & 34.09 \\
\hline$P$ & $<0.001$ & & & $<0.001$ & & & $<0.001$ & \\
\hline \multicolumn{9}{|c|}{ Family social class ${ }^{*}$} \\
\hline No job & $124 \cdot 22$ & $10 \cdot 61$ & 3772 & $7 \cdot 37$ & 0.94 & 3450 & 976 & $35 \cdot 13$ \\
\hline Farmer & 124.56 & 11.58 & 2451 & $7 \cdot 41$ & 0.91 & 2367 & 573 & $29 \cdot 19$ \\
\hline Unskilled & 123.63 & $10 \cdot 51$ & 948 & $7 \cdot 39$ & 0.92 & 864 & 255 & $36 \cdot 90$ \\
\hline Skilled & 124.93 & $10 \cdot 28$ & 3759 & $7 \cdot 76$ & 0.96 & 3641 & 1663 & 58.03 \\
\hline Unknown & 123.03 & $10 \cdot 52$ & 162 & 7.44 & 0.92 & 152 & 48 & $37 \cdot 21$ \\
\hline$P$ & 0.0013 & & & $<0.001$ & & & $<0.001$ & \\
\hline \multicolumn{9}{|c|}{ Mother is a smoker } \\
\hline No & $124 \cdot 77$ & $10 \cdot 77$ & 9219 & 7.55 & 0.95 & 8753 & 3028 & 42.88 \\
\hline Yes, cigar & 123.08 & $10 \cdot 34$ & 1374 & 7.33 & 0.96 & 1250 & 361 & $36 \cdot 46$ \\
\hline Yes, other & $122 \cdot 72$ & $10 \cdot 03$ & 270 & $7 \cdot 34$ & 0.92 & 243 & 70 & 36.65 \\
\hline Unknown & $122 \cdot 80$ & 11.02 & 229 & 7.43 & 0.93 & 228 & 56 & $30 \cdot 27$ \\
\hline$P$ & $<0.001$ & & & $<0.001$ & & & $<0.001$ & \\
\hline \multicolumn{9}{|c|}{ Mother was depressed during pregnancy* } \\
\hline No & $124 \cdot 80$ & $10 \cdot 66$ & 9392 & 7.55 & 0.95 & 8858 & 3065 & $42 \cdot 86$ \\
\hline Yes, mild & $122 \cdot 92$ & $10 \cdot 92$ & 1264 & $7 \cdot 31$ & 0.94 & 1187 & 342 & 37.09 \\
\hline Yes, severe & 122.02 & $10 \cdot 41$ & 229 & $7 \cdot 17$ & 0.98 & 209 & 43 & $25 \cdot 00$ \\
\hline Unknown & 121.63 & $11 \cdot 22$ & 207 & 7.51 & 0.92 & 220 & 65 & 35.91 \\
\hline$P$ & $<0.001$ & & & $<0.001$ & & & $<0.001$ & \\
\hline \multicolumn{9}{|c|}{ Was the pregnancy wanted?* } \\
\hline Yes & $125 \cdot 21$ & $10 \cdot 53$ & 6915 & $7 \cdot 61$ & 0.95 & 6580 & 2458 & $46 \cdot 47$ \\
\hline Yes, but later & 123.63 & $10 \cdot 64$ & 2714 & 7.43 & 0.940 & 2483 & 734 & 36.77 \\
\hline No & $122 \cdot 61$ & 11.44 & 1247 & $7 \cdot 23$ & 0.914 & 1181 & 263 & 27.45 \\
\hline Unknown & $121 \cdot 87$ & $11 \cdot 00$ & 216 & $7 \cdot 42$ & 0.93 & 230 & 60 & $32 \cdot 79$ \\
\hline$P$ & $<0.001$ & & & $<0.001$ & & & $<0.001$ & \\
\hline
\end{tabular}

NA, not available

* Based on the information provided by mothers (self-reported). Unknown group was not included in the statistical tests. 


\section{Results}

Table 1 shows the associations between confounding factors, exposure and educational outcomes. Children from higher social class, married families and wanted pregnancies, and female offspring and first or second born had significantly better school performance at the age of 16 years $(P<0.001$ for each comparison), and were more likely to have completed a university degree by the age of 31 years $(P<0.001)$.

Data on $\mathrm{Hb}$ levels were available for 9470 expectant mothers; of these, $84.79 \%$ ( $n$ 8030) did not have any form of anaemia at any stage during pregnancy. Thirty-nine expectant mothers $(0.41 \%)$ had persistent anaemia, and 1440 $(15.21 \%)$ had intermittent anaemia at third, seventh and/or ninth month of gestation (but were not anaemic at all points).

Adjusted for sex, maternal $\mathrm{Hb}$ at all stages of pregnancy was associated with school scores at the ages of 14 and 16 years $(P<0.01$ for all comparisons), while associations with higher education were observed for concentrations at the seventh and ninth months only. After full adjustment for potential confounders (sex, birth weight, calendar month of birth, mother's educational status, whether pregnancy was wanted or not, social class, parity, mother's marital status at pregnancy, mother's smoking status during pregnancy and mother's mental status), the associations between higher maternal $\mathrm{Hb}$ levels and school performance persisted for measures taken at 9 months, but not for measures taken at earlier stages of pregnancy (Table 2). Some suggestion for an association with school performance at the age of 16 years was also observed for maternal concentrations at 3 months in the imputed case analyses $(P=0.04)$, but not in the complete case analyses. After full adjustment, maternal $\mathrm{Hb}$ at any single time point was not associated with the higher final education. However, offspring of mothers with anaemia at least in some stage of pregnancy $(\mathrm{Hb}<110 \mathrm{~g} / \mathrm{l}$ at one or more points) appeared to have lower school scores, and they were also less likely to have completed a higher education degree at the age of 31 years (Table 2). The associations between maternal $\mathrm{Hb}$ and school achievement were similar in the subgroup of mothers who were non-anaemic throughout pregnancy compared with those observed in the full cohort (data not shown). There was no evidence for an interaction between $\mathrm{Hb}$ levels at different points of measurement and sex in relation to school scores or higher educational achievement ( $P>0 \cdot 15$ for all comparisons).

\section{Discussion}

Using data obtained from a large prospective cohort study, we found evidence for a direct association between maternal $\mathrm{Hb}$ levels during pregnancy and the educational achievement of the offspring. These data suggest long-term influences of pre-natal $\mathrm{Fe}$ metabolism, supporting earlier observations from animal experiments ${ }^{(16-20)}$. Previous studies in human subjects are sparse, although earlier data have suggested reduced cognitive performance after $\mathrm{Fe}$ deficiency during infancy/early childhood ${ }^{(21-26)}$.

It is unclear what individual pathways are involved in $\mathrm{Fe}$ deficiencies thought to affect brain development. Plausible routes described in previous human/animal studies include the following: alteration in neurotransmitter and/or brain

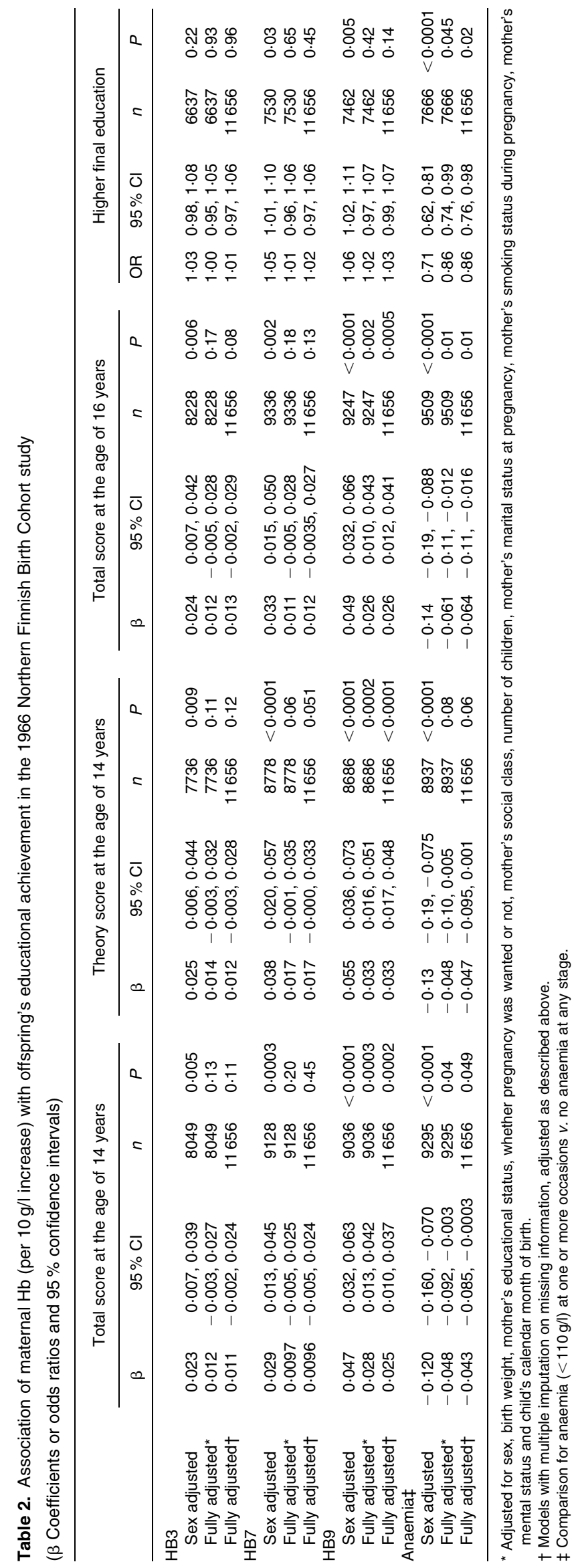


energy metabolism and/or decreased myelination ${ }^{(9,19,27)}$. In the present study, maternal $\mathrm{Hb}$ at the final trimester (but not at the earlier stages of pregnancy) was associated with the offspring's school performance, which indicates that there could be a sensitive period for the final stages of development ${ }^{(28)}$. This would be biologically plausible as during the final trimester of pregnancy and early infancy, myelination can be altered as a result of Fe deficiency ${ }^{(29,30)}$. It is also possible that the association could have been mediated by maternal influences on $\mathrm{Hb}$ concentrations in early infancy, which would provide an alternative explanation for the lack of effect for the first two trimesters. Lack of association for the earlier stages of pregnancy can also be explained by the initiation of $\mathrm{Fe}$ supplementation to mothers diagnosed as anaemic.

Unfortunately, information on infant concentrations or on maternal $\mathrm{Fe}$ supplementation during pregnancy was not available from the present study. Nevertheless, based on standard clinical procedures ${ }^{(31)}$, it is reasonable to assume that Fe supplementation would have been initiated for all women diagnosed as anaemic.

Longitudinal studies in human subjects examining motor development and cognitive function through to adulthood have indicated their negative relation with $\mathrm{Fe}$ deficiency anaemia in infancy ${ }^{(32-34)}$. Randomised control trials examining $\mathrm{Fe}$ status and school scores also reported a relationship between the two, with improvement in scores after Fe treatment ${ }^{(35,36)}$. Though these studies had included Fe status in addition to $\mathrm{Hb}$ levels in their analysis, they had failed to examine the effects of maternal Fe status during pregnancy on offspring. In addition to underlining the importance of maternal $\mathrm{Hb}$ level in the cognitive performance of the offspring, the present study suggested that the effect of Fe deficiency during pregnancy is long lasting. This is important, because despite previous suggestions for programming of cognitive function by maternal $\mathrm{Fe}$ status from animal experiments $^{(16-20)}$, there are very little data obtained from studies in human subjects. The effect sizes appear to be fairly modest in the present study, although the suggested $14 \%$ lower proportion of offspring achieving higher education for anaemic mothers (compared with others) may be important. Furthermore, due to the active monitoring (and treatment) of pregnant women in Finland at the time of the study, there were very few mothers with severe anaemia, and many of the women classified here as anaemic would have received treatment. Hence, extrapolation of effect sizes to other populations should be done with caution, and it is possible that associations between maternal anaemia and offspring's school performance might be stronger for the more extreme cases of deficiency.

Some methodological issues also need to be considered in the context of these findings. It should be noted that although in most cases anaemia can reasonably be assumed to be due to Fe deficiency, we did not have Fe status measures to confirm this. Some of the reduction in maternal $\mathrm{Hb}$ during the midpregnancy is likely to be due to haemodilution (expansion of blood volume), which typically leads to an approximately $10 \mathrm{~g} / \mathrm{l}$ reduction in circulating maternal concentrations. However, this would provide further support for our suggestive observation for a key role of late pregnancy, as the lowest $\mathrm{Hb}$ concentrations are typically observed about
28-32 weeks, after which, concentrations naturally raise again towards the end of the pregnancy in most mothers ${ }^{(37)}$. Missing data are a problem for all these types of longitudinal studies with follow-up lasting over several decades, although, on average, the participation rates in the NFBC 1966 study were fairly good (with $75 \%$ of the target population participating at the age of 31 years). Multiple imputation was used for missing data in the main analyses, and similar results that were obtained were compared to complete case analyses in most analyses. Exception was the borderline association between maternal $\mathrm{Hb}$ at 3 months and school performance, which was observed for the imputed models, but not in the complete case series. This suggests that reduced power due to missing information could have contributed to non-significant findings. Multiple imputation is based on the assumption that the data are missing at random, and although there is no reason to believe that this assumption is violated in the NFBC 1966 study, possible bias due to missing information cannot be ruled out. Information on the school scores at the age of 14 years was self-reported, and is therefore subject to reporting bias. However, school-reported and self-reported scores were strongly correlated in the present study, suggesting that self-reported scores were reliable. Furthermore, level of education was the only outcome measured at the age of 31 years, and it can be argued that more detailed measures are required for reliable estimation of potential influences on adult cognitive performance.

\section{Conclusion}

The data suggest that there may be long-term influences of maternal $\mathrm{Hb}$ during the final stages of pregnancy on the cognitive development of offspring, a finding in urgent need of replication. If true, this observation is important for the clinical care of pregnant women, as it suggests that $\mathrm{Fe}$ prophylaxis even at fairly late stages of pregnancy may be beneficial for the subsequent development of the offspring. The association between maternal $\mathrm{Hb}$ level during pregnancy and offspring's school performance is potentially of great public health importance as Fe deficiency is highly prevalent in pregnant women (40\% worldwide). Further investigations with a wider range of mental performance indicators are needed to evaluate the relationships and mechanisms of maternal $\mathrm{Fe}$ and offspring's mental performance.

\section{Acknowledgements}

We thank Professor Paula Rantakallio (launch of the NFBC 1966 study) and Mr Markku Koiranen (data management and advice) from the Institute of Health Sciences, University of Oulu, Finland. The Academy of Finland has financially supported NFBC 1966 study. Dr Ian Brown (Department of Epidemiology and Public Health, Imperial College London, UK) and Ms Diane Berry (UCL Institute of Child Health, London) are acknowledged for advice and help on data analysis. Support for the present research was provided by a $\mathrm{PhD}$ grant from the Yasuj University of Medical Sciences (a nonprofit organisation). E. H. is funded by the Department of Health (UK) Public Health Career Scientist Award. U. S. is funded by the Medical Research Council, UK. The Centre for Epidemiology of Child Health is funded by the Medical 
Research Council. GOSH/UCL Institute of Child Health receives a proportion of funding from the Department of Health's NIHR Biomedical Research Centres funding scheme. The authors' contributions are as follows: M. F. carried out the data analysis and wrote the article along with E. H. and M.-R. J. Data were managed by M. F. and U. S. The work was supervised by E. H., M.-R. J, J. W. and C. R. Data were collected by A. R., A. P., A.-L. H. and M.-R. J. All authors participated in the evaluation of the results, revised the manuscript and approved the final version. The authors report no conflicts of interest with the present paper.

\section{References}

1. Conrad M, Umbreit JN \& Moore E (1999) Iron absorption and transport. Am J Med Sci 318, 213-229.

2. Beard JL (2001) Iron biology in immune function muscle metabolism and neuronal functioning. $J$ Nutr 131, 568S-580S.

3. World Health Organization (2008) Worldwide Prevalence of Anaemia 1993-2005: WHO Global Database on Anaemia [B Brunode Benoist, E McLean, I Egli and M Cogswell, editors]. Geneva: WHO

4. Beard J (2003) Iron deficiency alters brain development and functioning. J Nutr 133, 1468S-1472S.

5. McLean E (2008) Worldwide prevalence of anaemia, WHO Vitamin and Mineral Nutrition Information System, 1993-2005. Public Health Nutr 12, 444-454.

6. Felt BT \& Lozoff B (1996) Brain iron and behavior of rats are not normalized by treatment of iron deficiency anemia during early development. J Nutr 126, 693-701.

7. Kwik-Uribe CL, Golub MS \& Keen CL (2000) Chronic marginal iron intakes during early development in mice alter brain iron concentrations and behavior despite postnatal iron supplementation. J Nutr 130, 2040-2048.

8. Grantham-McGregor S \& Ani C (2001) A review of studies on the effect of iron deficiency on cognitive development in children. $J$ Nutr 131, 649S-668S.

9. Lozoff B, Bear J \& Connor J (2006) Long-lasting neural and behavioral effects of iron deficiency in infancy. Nutr Rev S34-S43.

10. Sachdev HPS, Gera T \& Nestel P (2005) Effect of iron supplementation on mental and motor development in children: systematic review of randomised controlled trials. Public Health Nutr 8, 117-132.

11. Rantakallio P (1969) Groups at risk in low birth weight infants and perinatal mortality. Acta Paediatr Scand 193, Suppl. 193.

12. Jarvelin MR, Sovio U, King V, et al. (2004) Early life factors and blood pressure at age 31 years in the 1966 Northern Finland Birth Cohort. Hypertension 44, 838-846.

13. Rantakallio P (1988) The longitudinal study of the Northern Finland Birth Cohort of 1966. Paediatr Perinat Epidemiol 2, $59-88$.

14. Van Buuren S \& Oudshoorn K (1999) Flexible multivariate imputation by MICE. Technical Report. Leiden: TNO Quality of Life.

15. Everitt BS \& Hothorn T (2006) A Handbook of Statistical Analyses Using R. London: Chapman \& Hall/CRC.

16. Beard JL (2001) Iron biology in immune function muscle metabolism and neuronal functioning. J Nutr 131, 568S-580S
17. Kwik-Uribe CL, Golub MS \& Keen CL (2000) Chronic marginal iron intakes during early development in mice alter brain iron concentrations and behavior despite postnatal iron supplementation. J Nutr 130, 2040-2048.

18. Felt BT \& Lozoff B (1996) Brain iron and behavior of rats are not normalized by treatment of iron deficiency anemia during early development. J Nutr 126, 693-701.

19. Youdim MBH (2000) Nutrient deprivation and brain function: iron. Nutrition 16, 504-508.

20. Felt BT (2006) Persistent neurochemical and behavioral abnormalities in adulthood despite early iron supplementation for perinatal iron deficiency anemia in rats. Behav Brain Res 171, 261-270.

21. Algarin C, Peirano P, Garrido M, et al. (2003) Iron deficiency anemia in infancy: long-lasting effects on auditory and visual system functioning. Pediatr Res 53, 217-223.

22. Grantham-McGregor S \& Ani C (2001) A review of studies on the effect of iron deficiency on cognitive development in children. $J$ Nutr 131, 649S-666S

23. Lozoff B, Jimenez E \& Wolf AW (1991) Long-term developmental outcome of infants with iron deficiency. $N$ Engl J Med 325, 687-694

24. Lozoff B, Jimenez E, Hagen J, et al. (2000) Poorer behavioral and developmental outcome more than 10 years after treatment for iron deficiency in infancy. Pediatrics 105, E51.

25. Lozoff B, Beard J, Connor J, et al. (2006) Long-lasting neural and behavioral effects of iron deficiency in infancy. Nutr Rev 64, S34-S43.

26. Walter T (1994) Effect of iron-deficiency anaemia on cognitive skills in infancy and childhood. Baillieres Clin Haematol 7, $815-827$.

27. Beard J (2003) Iron deficiency alters brain development and functioning. J Nutr 133, 1468S-1472S.

28. Ben-Shlomo Y \& Kuh D (2002) A life course approach to chronic disease epidemiology: conceptual models, empirical challenges and interdisciplinary perspectives. Int J Epidemiol 31, 285-293.

29. Roncagliolo M, Garrido M, Walter T, et al. (1998) Evidence of altered central nervous system development in infants with iron deficiency anemia at $6 \mathrm{mo}$ : delayed maturation of auditory brainstem responses. Am J Clin Nutr 68, 683-690.

30. Walter T (2003) Effect of iron-deficiency anemia on cognitive skills and neuromaturation in infancy and childhood. Food Nutr Bull 24, S104-S110.

31. Milman N (2008) Prepartum anaemia: prevention and treatment. Ann Hemstatol 87, 949-959.

32. Beard J (2003) Iron deficiency alters brain development and functioning. J Nutr 133, 1468S-1472S.

33. Shafir T, Angulo-Barroso R, Jing $\mathrm{Y}$, et al. (2008) Iron deficiency and infant motor development. Early Hum Dev 84, 479-485.

34. Lozoff B (2006) Double burden of iron deficiency in infancy and low socioeconomic status: a longitudinal analysis of cognitive test scores to age 19 years. Arch Pediatr Adolesc Med 160, 1108-1113.

35. Pollitt E, Hathiral P, Kotchabhakdi NJ, et al. (1989) Iron deficiency and educational achievement in Thailand. Am J Clin Nutr 50, 687-697.

36. Soemantri AG, Pollitt E \& Kim I (1985) Iron deficiency anemia and educational achievement. Am J Clin Nutr 42, 1221-1228.

37. Koller O (1982) The clinical significance of hemodilution during pregnancy. Obstet Gynecol Surv 37, 649-652. 